\title{
Sleep-disordered breathing a neglected risk factor in primary open- angle glaucoma
}

\author{
Kaur M. ${ }^{1 *}$, Kaur I. ${ }^{2}$, Singh J. ${ }^{3}$ \\ DOI: https://doi.org/10.17511/jooo.2021.i04.04 \\ 1* Mandeep Kaur, MS Eye, Assistant Professor, Department of Ophthalmology, Sri Guru Ram Das Institute of Medical Sciences and \\ Research, Amritsar, Punjab, India. \\ 2 Inderjit Kaur, MS Eye, Ex-Professor \& Head, Department of Ophthalmology, Government Medical College, Amritsar, Punjab, India. \\ 3 Jagdeepak Singh, MS ENT, Ex-Professor \& Head, Department of Otolaryngology, Government Medical College, Amritsar, Punjab, India.
}

Background: Sleep-disordered breathing (SDB) is accompanied by large swings in blood pressure and the repetitive hypoxic period during sleep, which may accelerate anoxic optic nerve damage seen in glaucoma. There are many associated risk factors in primary open-angle glaucoma (POAG), but recently, SDB, though a neglected one, is coming up as a risk factor. However, various studies have reported controversial findings. Objective: To evaluate the relationship between SDB and POAG. Design: A hospital-based case-control study. Methods: A total of 400 patients between 3070 years were recruited from eye OPD between 2008- 2010. They were divided into two groups, 200 cases with established POAG and 200 age and sex-matched healthy subjects with normal IOP in the control group. Detailed history, complete ophthalmic and ENT examination was made along with BMI, blood pressure and neck girth measurement. Both groups were interviewed with a questionnaire regarding SDB and were recorded on the Epworth sleepiness scale (ESS). Results: The mean age being $55.02 \pm 8.66$ in the POAG group and male predominance noted both in POAG and SDB patients with ESS> 10 was statistically significant $(p<0.05)$. Also, patients in the POAG group with ESS $>10$ had more IOP and BMI, greater neck girth, high BP and more ENT problems with $p$-value $<0,001$, which is highly significant, thus showing the relationship between SDB and POAG. Conclusions: Increased community awareness and earlier detection of glaucoma and its correlation with SDB results in decreased morbidity.

Keywords: Sleep, Breathing, Glaucoma, Disordered

\section{Corresponding Author}

Mandeep Kaur, MS Eye, Assistant Professor, Department of Ophthalmology, Sri Guru Ram Das Institute of Medical Sciences and Research, Amritsar, Punjab, India.

Email: sidhumandeep_73@hotmail.com

\section{How to Cite this Article}

Mandeep Kaur, Inderjit Kaur, Jagdeepak Singh, Sleep-disordered breathing a neglected risk factor in primary open-angle glaucoma. Trop J Ophthalmol Otolaryngol. 2021;6(4):75-84.

Available From

https://opthalmology.medresearch.in/index.php/jooo /article/view/207

\section{To Browse}

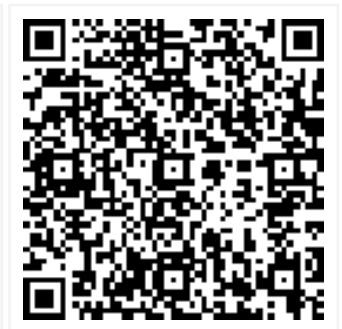

Manuscript Received 2019-10-29

Conflict of Interest No

Review Round 1
2019-11-09
Funding
Nil

Review Round 2
2019-11-18
$\begin{gathered}\text { Ethical Approval } \\ \text { Yes }\end{gathered}$

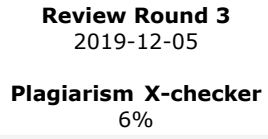

Accepted 2019-12-25

Note

(C) 2021 by Mandeep Kaur, Inderjit Kaur, Jagdeepak Singh and Published by Siddharth Health Research and Social Welfare Society. This is an Open Access article licensed under a Creative Commons Attribution 4.0 International License https://creativecommons.org/licenses/by/4.0/ unported [CC BY 4.0]. 


\section{Introduction}

Sleep-disordered breathing (SDB), or upper-airway obstruction during sleep or sleep apnoea initially demonstrated in the 1960s, is a common chronic disorder that results in recurrent nocturnal asphyxia, fragmented sleep, major fluctuations in blood pressure and increased sympathetic nervous system activity.[1] SDB represents a group of conditions having an abnormal respiratory pattern during sleep ranging from primary snoring to severe obstructive sleep apnoea.[2] Obstructive sleep apnoea (OSA) or obstructive sleep apnoea syndrome (OSAS) is a neglected and potentially disabling condition characterized by excessive daytime sleepiness [3], disruptive snoring, repeated episodes of partial or complete upper airway obstruction lasting 10 seconds to 60 seconds or more [4] due to hypotonia of the upper airway musculature during REM sleep [5] and nocturnal hypoxemia [6] which gets terminated by transient arousal that resumes ventilation. Sleep-disordered breathing affects up to $20 \%$ of the population between 30 and 60 years of age [7] and presents with daytime somnolence, tiredness, fatigue [8], the difficulty of concentration, headache, reduced work performance.

It is associated with several eye disorders that include floppy eyelid syndrome, optic neuropathy, non-arteritic anterior ischaemic optic neuropathy and papilloedema secondary to increased intracranial pressure, normal-tension glaucoma and primary open-angle glaucoma (POAG) [9-12]. POAG is defined as a chronic progressive optic neuropathy [13] in adults and is multifactorial. [14,15] It develops due to the death of retinal ganglion cells by elevated IOP and vascular insufficiency resulting from reduced ocular blood flow, decreased ocular perfusion pressure, generalized vascular deregulation or increased trans lamina cribrosa pressure [16]. and leads to typical visual field defects and increased cupping of the optic disc. [17]. OAG is the most common type of glaucoma and is estimated to be responsible for $50 \%$ of glaucoma cases [18]. The prevalence of glaucoma in the general population is between $1 \%$ and $2 \%$. [19]. According to WHO, glaucoma is the second leading cause of blindness worldwide, and approximately 60 million people are diagnosed with glaucoma, and an estimated 8.4 million people are blind due to glaucoma.

Several risk factors are associated with SDB [20],
Like middle-aged males [7], black race, obesity, increased BMI, smoking, family history, large neck circumference, presence of upper airway abnormalities like enlarged tonsils and adenoids, nasal obstruction [21], diabetes, excessive alcohol consumption, hypothyroidism, acromegaly, hypertension, previous history of trauma or surgery of upper airways, abuse of chemicals like alcohol, sleeping pills, narcotics, barbiturates, sedatives and cigarettes. Few of these are also associated with POAG except high IOP, increasing age, optic nerve cupping and asymmetry, central corneal thickness less than 555 microns, high myopia and recently sleep-disordered breathing is being considered a probable risk factor for POAG.

Many studies have reported the association between glaucoma and OSAS, and most of them focused on the Prevalence of glaucoma in OSAS patients and indicated it as a risk factor. $[9,22]$ McNab recently proposed an association between POAG and sleep apnea. [11] Hence, we conducted a study to investigate if there is any relationship between SDB and POAG.

Objective: To evaluate the relationship between sleep-disordered breathing and primary open-angle glaucoma.

\section{Material and methods}

Study design and setting: A random case-control study was conducted between 2008 and 2010 in a teaching medical institute in North India. A total of 400 patients between $30-70$ years were recruited from eye OPD, dividing into two groups, 200 cases with established glaucoma in POAG group and 200 age and sex-matched healthy subjects with normal IOP in the control group.

Ethical consideration and permission: Ethical approval was taken from the institute's ethical committee and written informed consent from all subjects participating in the study.

\section{Inclusion Criteria for POAG group}

01 . An intraocular pressure (IOP) $\geq 21 \mathrm{mmHg}$ with or without

02. A cup to disc ratio (CDR) more than 0.5 or difference of CDR between two eyes $>0.2$ with thinning of the neuroretinal rim; the presence of any disc haemorrhages to strongly support the diagnosis

03. With glaucomatous visual field 
04. Open Irido-corneal angle

05. No history of ocular surgery or ocular

\section{Inclusion Criteria for Control group}

01 . IOP $<21 \mathrm{mmHg}$.

02. No evidence of glaucomatous optic

03. Normal anterior chamber angle on slit lamp and gonioscopic

04. Normal visual field test results

05. No history of previous anti-glaucoma drugs, ocular surgery or ocular

\section{Methodology}

All subjects underwent complete ophthalmological examination, including best-corrected visual acuity using Snellen's chart, anterior chamber depth assessment using Van Herick technique, measurement of intraocular pressure (IOP) (Schiotz/ applanation tonometer), fundus assessment with an indirect ophthalmoscope and $+78 \mathrm{D}$ lens for the presence of glaucomatous optic disc changes (cup-disk ratio $>0.5$ or cup-disc asymmetry $>0.2$, or partial or complete notching, and rim haemorrhages), Gonioscopy with Goldman three-mirror gonioscope and automated perimetry for visual field testing (30-2). ENT examination of nose and oropharynx for polyps, septal deviation, any mass in the nasal cavity, macroglossia, adenoids and enlarged tonsils was done. Measurement of blood pressure (BP) in $\mathrm{mm} \mathrm{Hg}$, basal metabolic index (BMI = weight in $\mathrm{Kg}$ divided by height square in meters) and neck circumference (NG) in centimetres was done for both POAG and Control groups.

For sleep-disordered breathing (SDB), all subjects were interviewed with a simple, self-administered questionnaire (Box 1) which is shown to provide a measurement of the subject's general level of daytime sleepiness[23] and were rated on the Epworth sleepiness scale (ESS)) devised at Epworth hospital in Melbourne, Australia and created by Murray Jones. The concept of the ESS was derived from observations about the nature and occurrence of daytime sleep and sleepiness. It is based on questions referring to eight such situations [23]. Subjects were asked to rate on a scale of 0-3 on the likelihood of being dozing off or falling asleep in the eight situations, depending upon the usual way of their life recently and distinguishing between dozing off and simply feeling tired. The numbers selected for the eight such situations [23].
Subjects were asked to rate on a scale of 0-3 on the likelihood of being dozing off or falling asleep in the eight situations, depending upon the usual way of their life recently and distinguishing between dozing off and simply feeling tired. The numbers selected for the eight situations in the ESS were added together to give a score for each subject, between 0 and situations in the ESS were added together to give a score for each subject, between 0 and

24. All the data thus obtained was arranged in tabulated form, and chi-square ( $\times 2$ ) test analysis was performed for data comparison between POAG and control group patients. A probability value of less than 0.05 was considered significant.

\section{Box1 The Epworth sleepiness scale}

\begin{tabular}{|l|l|}
\hline THE EPWORTH SLEEPINESS SCALE \\
Name: \\
Today's date: Your age (years): _ \\
Your sex (male = M; female = F): _ \\
How likely are you to doze off or fall asleep in the following situations, in \\
contrast to feeling just tired? This refers to your usual way of life in recent \\
times. Even if you have not done some of these things recently, try to \\
work out how they would have affected you. Use the following scale to \\
choose the most appropriate number for each situation: \\
0 = would never doze \\
1 = slight chance of dozing \\
2 = moderate chance of dozing $3=$ high chance of dozing \\
\hline SITUATION & CHANCE OF \\
\hline Siting and reading & DOZING \\
\hline Watching television & \\
\hline Sitting inactive in a public space (e.g. a theatre or a & \\
meeting) & \\
\hline As a passenger in a car/bus for an hour without a break & \\
\hline Lying down to rest in the afternoon when circumstances & \\
\hline Sitting and talking to someone \\
\hline Sitting quietly after a lunch without alcohol \\
\hline In a car, while stopped for a few minutes in the traffic & \\
\hline My Total & \\
\hline
\end{tabular}

\section{Results}

We found that the mean age in the POAG group was $55.02 \pm 8.66$ years, and among the control group, it was $57.03 \pm 9.28$ years, and there was no statistically significant difference between the two groups. Table 1 shows the distribution of patients in two groups according to Epworth Sleepiness Scale for sleep-disordered breathing having 110 patients 
$(55 \%)$ in the POAG group with an ESS score of more than ten while 51 patients in the control group with ESS > 10. Statistically, this finding was highly significant $(p<0.001)$.

Table 1: Distribution according to Epworth Sleepiness Scale

\begin{tabular}{|l|l|l|l|l|l|}
\hline ESS Score & POAG Group & \%age & Control group & \%age & Total \\
\hline $0-10$ & 90 & 45 & 149 & 74.5 & 239 \\
\hline$>10$ & 110 & 55 & 51 & 25.5 & 161 \\
\hline Grand total & 200 & 100 & 200 & 100 & 400 \\
\hline
\end{tabular}

$\chi_{2}=36.19 ; p<0.001 ;$ Highly Significant

Table 2 shows the sex wise distribution in both study groups having more males (114) in the POAG group as compared to the control group, which had more females (108), and this was statistically significant $(p<0.05)$.

Table 2: Sex Distribution in POAG and Control

\section{Group}

\begin{tabular}{|l|l|l|l|}
\hline \multicolumn{1}{|c|}{ Sex } & \multicolumn{1}{c|}{ POAG Group } & \multicolumn{1}{c|}{ Control group } & \multicolumn{1}{c|}{ Total } \\
\hline Male & 114 & 92 & 206 \\
\hline Female & 86 & 108 & 194 \\
\hline Total & 200 & 200 & 400 \\
\hline
\end{tabular}

$\chi 2=4.85 ; \mathrm{p}<0.05 ;$ significant

Table 3 shows male predominance (71 out of 110 ) in the POAG group with ESS score >10 ( $p$-value < $0.05)$, while the control group had more females (30 out of 51 ) with an ESS score $>10$.

Table 3: Sex Distribution according to Epworth Sleepiness Scale

\begin{tabular}{|l|l|l|}
\hline & POAG group with ESS $>\mathbf{1 0}$ & Control group with ESS $>\mathbf{1 0}$ \\
\hline Male & 71 & 21 \\
\hline Female & 39 & 30 \\
\hline Total & 110 & 55 \\
\hline
\end{tabular}

Table 4 shows that in the POAG group, male patients had greater neck girth (103), higher BMI (87), more elevated BP (93) and more ENT manifestations (47) as compared to the control group and were statistically highly significant ( $p<$ 0.001).

Table 4: Gender-based distribution of Neck Circumference, BMI, High BP, Ent Problems And ESS

\begin{tabular}{|l|l|l|l|l|}
\hline \multirow{2}{*}{} & \multicolumn{2}{|c|}{ POAG group } & \multicolumn{2}{c|}{ Control group } \\
\cline { 2 - 6 } & Males & Females & Males & Females \\
\hline Neck Girth $>42 \mathrm{~cm}$ & 103 & 64 & 22 & 18 \\
\hline BMI $>24$ & 87 & 64 & 19 & 17 \\
\hline Presence of ENT problems & 47 & 25 & 19 & 16 \\
\hline
\end{tabular}

\begin{tabular}{|l|l|l|l|l|}
\hline Blood Pressure $>120 / 80 \mathrm{~mm} \mathrm{Hg}$ & 93 & 56 & 27 & 22 \\
\hline ESS $>10$ & 71 & 39 & 21 & 30 \\
\hline
\end{tabular}

Table 5 shows that 122 out of 200 patients with high intraocular pressure had an ESS score of more than 10 .

Table 5: IOP and ESS score

\begin{tabular}{|l|l|l|l|}
\hline \multicolumn{1}{|c|}{ IOP in $\mathrm{mm} \mathrm{Hg}$} & \multicolumn{1}{c|}{ ESS $<10$} & \multicolumn{1}{c|}{ ESS $>10$} & \multicolumn{1}{c|}{ Total } \\
\hline $21-30$ & 65 & 103 & 168 \\
\hline $31-40$ & 13 & 19 & 32 \\
\hline Total & 78 & 122 & 200 \\
\hline
\end{tabular}

Table 6 showed the distribution of 151 patients with ESS > 10 having greater neck circumference (93), higher BMI (90), more elevated BP (84) and more ENT manifestations (47) in the POAG group and were statistically highly significant ( $p<0.001)$.

\section{Table 6: Parameters in both groups}

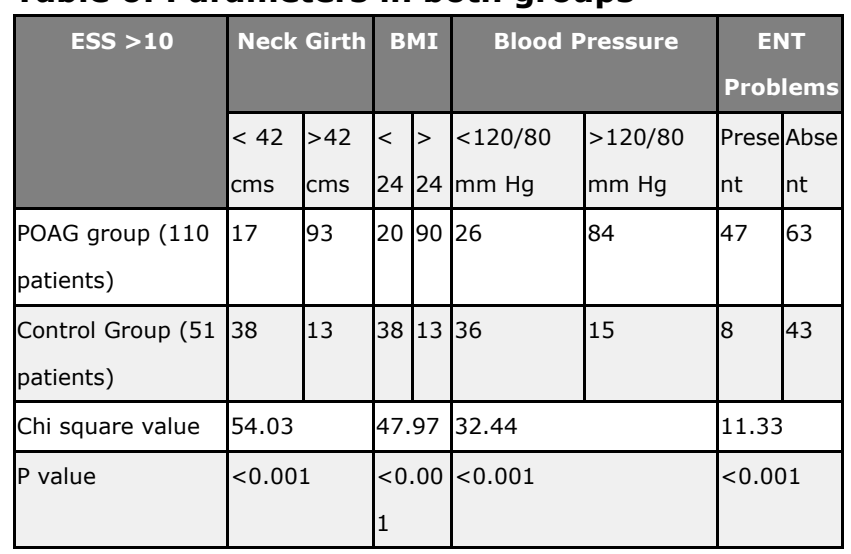

Table 7: ENT problems in both groups.

\begin{tabular}{|l|l|l|}
\hline \multicolumn{1}{|c|}{ ENT problems } & POAG group & \multicolumn{1}{c|}{ Control group } \\
\hline DNS & 57 & 29 \\
\hline Nasal polyp & 02 & 02 \\
\hline Mass in nasal cavity & 01 & Nil \\
\hline Macroglossia & 04 & 03 \\
\hline Adenoids & Nil & 01 \\
\hline Enlarged Tonsils & 08 & Nil \\
\hline Total & 72 & 35 \\
\hline
\end{tabular}

\section{Discussion}

We studied the relationship between Sleepdisordered breathing (SDB), a measure of obstructive sleep apnoea (OSA) and POAG, along with their relation to IOP, BMI, neck circumference and blood pressure. For SDB, excessive daytime sleepiness was assessed using the Epworth sleepiness scale (ESS), the concept of which was derived from observations about the nature and occurrence of daytime sleep and drowsiness [23]. In our study, we found the prevalence of SDB was higher in the POAG group [110 patients; 55\% with ESS $=10$ (Table 1)] than that in the control group 
(26\% with ESS score $>10)$. The results were consistent with studies done by Onen et al. [19] They studied 212 outpatients with POAG and 212 outpatients without POAG and found a high prevalence of sleep-disordered breathing described by self-reported symptoms of snoring, excessive daytime sleepiness, and insomnia in the POAG group. Ohana et al [24] also reported high prevalence of OSAS in POAG patients and suggested that examination should include the history of the presence of snoring. Mojon et al [9] also found a higher prevalence of glaucoma (7.2\%) in 69 patients with obstructive sleep apnoea compared to a $2 \%$ prevalence of glaucoma in a European population. They also found a positive correlation between the number of apneas experienced per hour and IOP, visual field loss variance, glaucomatous optic disc changes and the diagnosis of glaucoma, hence concluded that there might be a possibility that a dose-dependent relationship exists between OSA and the diagnosis and progression of glaucoma. Mojon also reported a $20 \%$ vs $11 \%$ prevalence of newly diagnosed sleep apnoea in POAG patients and hence found a significantly higher prevalence of OSA in the glaucoma patients compared with the control groups.[9] In a 5-year retrospective study, a statistically significant increase in the incidence of open-angle glaucoma in OSA patients compared with non-OSA patients was found. [25] Robert et al. [26] included 69 snorers in their study on eyelid hyperlaxity and obstructive sleep apnea syndrome and treated six patients $(8.7 \%)$ for POAG, thus showing a significant incidental association between SDB and POAG. Another study on floppy eyelid syndrome and sleep apnea described that 1 of 8 patients having sleep apnea syndrome also had glaucoma.[27]. On the other hand, in a cross-sectional study published by Geyer et al [28] only $2 \%$ prevalence of glaucoma among 228 patients with sleep apnoea was found compared to the general Caucasian population and was not significant. Another study on 667 patients with newly diagnosed glaucoma from the diagnostic ICD9 database and a control group of 10 matched controls for each case of glaucoma found that there were seven cases $(1.1 \%)$ of OSAS in 667 patients as compared with $32(0.5 \%)$ in the control group which was not significant. [29].

Age is considered a risk factor for both POAG and OSA. The incidence of OSAS in the general population has also been reported to be the highest between 45 - 65 years of age. [30]
The mean age in our study was $55.02 \pm 8.66$ years in the POAG group with ESS $>10$, and $38.5 \%$ of patients were in the age group 41-50 years followed by 51-60 years and was very close to study by $M$ Gyasi et al. [31] who found mean age of 53.2 years (median of 56) and a standard deviation of 16.3 with $23.6 \%$ below 40 years and Balbay et al [32] also found a mean age of 56 years in their study, but, $S Y$ Wu et al [33] reported that prevalence of glaucoma increased with age in black participants, reaching $17 \%$ for those aged 70 years or older. In the general population, the prevalence of OSA is known to be $17 \%$ to $24 \%$ in men and $5 \%$ to $9 \%$ in women $[7,30]$. Some studies report male prevalence of POAG to be twice as high as females or vice versa, while others report no gender association at all. In our study, about 114 males were in the POAG group (Table 2), while the control group had more females. The results were similar to the study by Gyasi et al. [31], who found nearly twice as many males $(n=292,65.5 \%$ diagnosed with glaucoma compared to females $(n=154$, $34.5 \%$. However, the study done by Al Monsouri $\mathrm{F}$ [34] found fewer males (41.6\%) than females (58.4\%). Also, we found male predominance (71out of 110 patients) in the POAG group with ESS $>10$ (Table 3) comparable to the study by Nahlah et al. [35] who also found more males in the OSA group than the control group $(p<0.05)$.

In contrast, Onen et al found more females than males in POAG and control groups [19]. Intraocular pressure is an important risk factor for glaucomatous optic neuropathy and obesity, measured as body mass index (BMI), may increase blood viscosity and episcleral venous pressure and damage aqueous outflow facility $[36,37]$. A few studies $[38,39]$ suggested a relationship of IOP or ocular hypertension to BMI or obesity. We found 122 patients with increased IOP and 90 out of 110 patients with BMI $>24$ in the POAG group with SDB (ESS > 10), and the incidence of BMI > 24 was higher in males (87). The studies in favour of our study are the Beaver Dam Eye Study that found a higher IOP association with higher BMI [38] and a study of Japanese adolescents and adults aged 1494, which found higher BMI associated with elevated IOP regardless of age, sex, and blood pressure [39]. Other studies investigated a potential link between the presence of open-angle glaucoma and BMI or obesity $[40,41]$. In contrast, in a case-control study, no difference in BMI status was found in individuals with and without glaucoma [42]. 
IOP might get influenced by the haemodynamic system, autonomic nervous system and stage of sleep. [43]. SDB can affect these factors through changes in sleep architecture and an increase in blood pressure and sympathetic tone. The earlier studies conducted on glaucoma prevalence in OSAS reported a significant association between $\mathrm{AHI}$ and IOP. $[10,44,45]$ A study reported that an increase in IOP during lying can result in the development or progression of glaucoma in OSA patients [46]. But others found no correlation between IOP and RDI [28].

The change in pharyngeal size and shape due to obesity contributes to SDB. Fat storage in the neck may be particularly associated with risk for SDB, though a subset of patients with SDB are of normal body weight and have a family history of snoring or SDB. Factors affecting upper-airway size or patency include various anatomical variants and abnormalities like nasal obstruction, macroglossia, retrognathia, obesity, alcohol or sedative intake and body position during sleep. We found large neck circumference in 103 male patients, and 93 out of 110 patients in the POAG group with ESS $>10$ had neck girth $>42 \mathrm{cms}$. Also, the male population in the study group had high blood pressure with more ENT problems (Table 4). Moreover, the incidence of these parameters was highly significant ( $\mathrm{P}$-value < 0.001 ) in the POAG group with SDB (ESS > 10, Table 6). Various clinical and epidemiological factors associated with sleep-disordered breathing like increasing age, male sex, large neck circumference, obesity and reported snoring with daytime sleepiness were similar to previous studies $[7,47,48]$. These co-morbidities are also risk factors for glaucoma and may contribute to our finding of a higher prevalence of glaucoma in the SDB group [49]. In the first half of the 1980 s, a relationship was proposed between snoring, sleep apnoea and hypertension, initially supported by epidemiological studies that used self-reported snoring as a marker for sleep apnoea $[50,51]$ and later, a correlation between sleep apnoea and increased cardiovascular risk was suggested [52]. Strong associations with systemic hypertension had been reported in glaucoma patients. $[53,54]$ It is also reported that in the presence of other vascular risk factors, the optic nerve head blood flow may be reduced below a critical level due to physiological nocturnal hypotension and hence play a role in the pathogenesis of anterior ischemic optic neuropathy and glaucoma. [55].
On the other hand, SDB due to large swings in nocturnal blood pressure [56] and recurrent severe hypoxia [57] may aggravate anoxic optic nerve damage, which is implicated in glaucoma. Hence, various studies suggested that patients with OSA are at significant risk of developing primary openangle glaucoma (POAG) and vice versa. $[9,10,12,19]$.

The limitation of our study is the use of a subjective method in the form of a questionnaire instead of objective measurement to determine the presence of sleep-disordered breathing in a group of 400 patients. We found an association between primary open-angle glaucoma (POAG) and sleep-disordered breathing (SDB), but the reciprocal relationship between SDB and glaucoma could not be established.

\section{Conclusion}

A multidisciplinary approach that coordinates input from diverse behavioural, medical, surgical, otolaryngologist and, above all, the ophthalmologist would be of value in complex assessment and therapy for POAG and SDB. Moreover, the influence of SDB in the prevalence, incidence, and development of glaucoma is unknown compared with other potentially modifiable risk factors. [9$16,19,20,24$ ] Earlier, Marcus et al [12] studied sleep disorders as a risk factor for normal-tension glaucoma and Boland et al recently conducted a detailed evaluation of factors contributing to the development of glaucoma and found sleep apnea to be one of the risk factors.[58]. Hence, there is a need and scope for further studies to evaluate the risk of SDB in glaucoma.

\section{What does this study add to the existing knowledge?}

An early detection, increased community awareness, appropriate treatment, and patient's compliance with treatment may slow down the progression of optic nerve head damage. Hence, we highly recommend that a sleep history from patients with POAG and vice versa be incorporated in a routine examination.

\section{Contribution details}

Dr Inderjit Kaur has conceptualized the study, prepared, verified all the drafts and approved the final draft. 
Late Dr Geetwinder Kaur designed the study protocol, conducted the ophthalmological examination and data collection. Dr Mandeep Kaur has done the manuscript writing. Dr Jagdeepak Singh has done the ENT examination of all patients and, along with Dr Inderjit Kaur, have provided vital inputs and supported the study.

\section{Acknowledgement}

We owe special thanks to Late $\operatorname{Dr}$ Geetwinder Kaur for her contribution to this study.

\section{Reference}

01. Thorpy MJ. Classification of sleep disorders. Neurotherapeutics. 2012 Oct;9(4):687-701. doi: 10.1007/s13311-012-0145-6 [Crossref][PubMed] [Google Scholar]

02. Lumeng JC, Chervin RD. Epidemiology of pediatric obstructive sleep apnea. Proc Am Thorac Soc. 2008 Feb 15;5(2):242-52. doi: 10.1513/pats.200708-135MG [Crossref][PubMed] [Google Scholar]

03. Saletu M, Sauter C, Lalouschek W, Saletu B, Kapfhammer G, Benesch T, Zeitlhofer J. Is excessive daytime sleepiness a predictor of carotid atherosclerosis in sleep apnea?. Atherosclerosis. 2008;196(2):810-6. doi: 10.1016/j.atherosclerosis. 2007.01.016 [Crossref][PubMed][Google Scholar]

04. Lugaresi E, Plazzi G. Heavy snorer disease: from snoring to the sleep apnea syndrome--an overview. Respiration. 1997;64 Suppl 1:11-4. doi: 10.1159/ 000196730 [Crossref][PubMed][Google Scholar]

05. Strollo PJ Jr, Rogers RM. Obstructive sleep apnea. N Engl J Med. 1996 Jan 11;334(2):99-104. doi: 10.1056/NEJM199601113340207 [Crossref] [PubMed][Google Scholar]

06. Guilleminault C, Do Kim Y, Chowdhuri S, Horita M, Ohayon M, Kushida C. Sleep and daytime sleepiness in upper airway resistance syndrome compared to obstructive sleep apnoea syndrome. Eur Respir J. 2001 May;17(5):838-47. doi: 10.1183/09031936.01.17508380

[Crossref]

[PubMed][Google Scholar]

07. Young T, Palta M, Dempsey J, Skatrud J, Weber $\mathrm{S}$, Badr S. The occurrence of sleep-disordered breathing among middle-aged adults. N Engl J Med. 1993;328(17):1230-5. doi: 10.1056/NEJM1993 04293281704 [Crossref][PubMed][Google Scholar]
08. Chervin RD. Sleepiness, fatigue, tiredness, and lack of energy in obstructive sleep apnea. Chest. 2000 Aug;118(2):372-9. doi: 10.1378/chest.118.2.372 [Crossref][PubMed] [Google Scholar]

09. Mojon DS, Hess CW, Goldblum D, Böhnke M, Körner $F$, Mathis J. Primary open-angle glaucoma is associated with sleep apnea syndrome. Ophthalmologica. 2000;214(2):115-8. doi: 10.1159/000027478 [Crossref][PubMed][Google Scholar]

10. Mojon DS, Hess CW, Goldblum D, Fleischhauer J, Koerner F, Bassetti C, Mathis J. High prevalence of glaucoma in patients with sleep apnea syndrome. Ophthalmology. 1999 May;106(5):1009-12. doi: 10.1016/S0161-6420(99)00525-4 [Crossref] [PubMed][Google Scholar]

11. McNab AA. The eye and sleep apnea. Sleep Med Rev. 2007 Aug;11(4):269-76. doi: 10.1016/j.smrv.2007.03.006 [Crossref][PubMed] [Google Scholar]

12. Marcus DM, Costarides AP, Gokhale $P$, Papastergiou G, Miller JJ, Johnson MH, Chaudhary BA. Sleep disorders: a risk factor for normal-tension glaucoma?. J Glaucoma. 2001 Jun;10(3):177-83. doi: $\quad 10.1097 / 00061198-200106000-00006$ [Crossref][PubMed][Google Scholar]

13. Foster PJ, Buhrmann R, Quigley HA, Johnson GJ. The definition and classification of glaucoma in prevalence surveys. $\mathrm{Br} \mathrm{J}$ Ophthalmol. 2002 Feb;86(2):238-42. doi: 10.1136/bjo.86.2.238 [Crossref][PubMed][Google Scholar]

14. Mao LK, Stewart WC, Shields MB. Correlation between intraocular pressure control and progressive glaucomatous damage in primary openangle glaucoma. Am J Ophthalmol. 1991 Jan 15;111(1):51-5. doi: 10.1016/s0002-9394(14) 76896-5 [Crossref][PubMed][Google Scholar]

15. Drance SM, Schulzer M, Thomas B, Douglas GR. Multivariate analysis in glaucoma, Use of discriminant analysis in predicting glaucomatous visual field damage. Arch Ophthalmol. 1981 Jun;99(6):1019-22. doi: 10.1001/archopht.1981.03 930011019007 [Crossref][PubMed][Google Scholar]

16. Agarwal R, Gupta SK, Agarwal P, Saxena R, Agrawal SS. Current concepts in the pathophysiology of glaucoma. Indian J Ophthalmol. 2009 Jul-Aug;57(4):257-66. doi: 10.4103/03014738.53049 [Crossref][PubMed][Google Scholar] 
17. Shaffer RN. Open-Angle Glaucoma. Trans Am Acad Ophthalmol Otolaryngol. 1963 JulAug;67:467-75. [Crossref][PubMed][Google Scholar]

18. Cook C, Foster P. Epidemiology of glaucoma: what's new?. Can J Ophthalmol. 2012 Jun;47(3):223-6. doi: 10.1016/j.jcjo.2012.02.003 [Crossref][PubMed][Google Scholar]

19. Onen SH, Mouriaux F, Berramdane L, Dascotte JC, Kulik JF, Rouland JF. High Prevalence of sleepdisordered breathing in patients with primary openangle glaucoma. Acta Ophthalmol Scand. 2000 Dec;78(6):638-41. doi: 10.1034/j.16000420.2000.078006638.x [Crossref][PubMed] [Google Scholar]

20. Dhillon S, Shapiro CM, Flanagan J. Sleepdisordered breathing and effects on ocular health. Can J Ophthalmol. 2007 Apr;42(2):238-43. [Crossref][PubMed][Google Scholar]

21. Olsen KD, Kern EB, Westbrook PR. Sleep and breathing disturbance secondary to nasal obstruction. Otolaryngol Head Neck Surg. 1981 SepOct;89(5):804-10.

doi:

10.1177/019459988108900522 [Crossref][PubMed] [Google Scholar]

22. Grieshaber MC, Flammer J. Blood flow in glaucoma. Curr Opin Ophthalmol. 2005 Apr;16(2):79-83. doi: 10.1097/01.icu.0000156134.38495.0b [Crossref] [PubMed][Google Scholar]

23. Johns MW. A new method for measuring daytime sleepiness: the Epworth sleepiness scale. Sleep. 1991 Dec;14(6):540-5. doi: 10.1093/sleep/14.6.540 [Crossref][PubMed][Google Scholar]

24. Blumen Ohana E, Blumen MB, Bluwol E, Derri M, Chabolle F, Nordmann JP. Primary open angle glaucoma and snoring: Prevalence of OSAS. Eur Ann Otorhinolaryngol Head Neck Dis. 2010 Nov;127(5):159-64. doi: 10.1016/j.anorl.2010.07.003 [Crossref][PubMed] [Google Scholar]

25. Lin CC, Hu CC, Ho JD, Chiu HW, Lin HC. Obstructive sleep apnea and increased risk of glaucoma: a population-based matched-cohort study. Ophthalmology. 2013 Aug;120(8):1559-64. doi: 10.1016/j.ophtha.2013.01.006 [Crossref] [PubMed][Google Scholar]
26. Robert PY, Adenis JP, Tapie P, Melloni B. Eyelid hyperlaxity and obstructive sleep apnea (OSA) syndrome. Eur J Ophthalmol. 1997 JulSep;7(3):211-5. [Crossref][PubMed][Google Scholar]

27. McNab AA. Floppy eyelid syndrome and obstructive sleep apnea. Ophthalmic Plast Reconstr Surg. 1997 Jun;13(2):98-114. doi: 10.1097/00002341-199706000-00005 [Crossref] [PubMed][Google Scholar]

28. Geyer O, Cohen N, Segev E, Rath EZ, Melamud $L$, Peled $R$, et al. The Prevalence of glaucoma in patients with sleep apnea syndrome: same as in the general population. Am J Ophthalmol. 2003 Dec;136(6):1093-6. doi: 10.1016/s00029394(03)00709-8 [Crossref][PubMed][Google Scholar]

29. Girkin CA, McGwin G Jr, McNeal SF, Owsley C. Is there an association between pre-existing sleep apnoea and the development of glaucoma?. $\mathrm{Br}$ J Ophthalmol. 2006 Jun;90(6):679-81. doi: 10.1136/bjo.2005.086082 [Crossref][PubMed] [Google Scholar]

30. Bixler EO, Vgontzas AN, Ten Have T, Tyson K, Kales A. Effects of age on sleep apnea in men: $I$. Prevalence and severity. Am J Respir Crit Care Med. 1998 Jan;157(1):144-8. doi: 10.1164/ajrccm.157.1.9706079 [Crossref][PubMed] [Google Scholar]

31. Gyasi M, Amoako W, Adjuik M. Presentation patterns of primary open angle glaucomas in north eastern ghana. Ghana Med J. 2010 Mar;44(1):2530. doi: 10.4314/gmj.v44i1.68853 [Crossref] [PubMed][Google Scholar]

32. Balbay EG, Balbay O, Annakkaya AN, Suner KO, Yuksel $H$, Tunç $M$, et al. Obstructive sleep apnoea syndrome in patients with primary open-angle glaucoma. Hong Kong Med J. 2014 Oct;20(5):37985. doi: 10.12809/hkmj134021 [Crossref][PubMed] [Google Scholar]

33. Wu SY, Nemesure B, Leske MC. Observed versus indirect estimates of incidence of open-angle glaucoma. Am J Epidemiol. 2001 Jan 15;153(2):184-7. doi: 10.1093/aje/153.2.184 [Crossref][PubMed][Google Scholar]

34. Al Mansouri, F. "The Pattern and Severity of Primary Glaucoma in Qatar". Qatar Medical Journal. 2002;1:15. [Crossref][PubMed][Google Scholar] 
35. Bagabas N, Ghazali W, Mukhtar M, AlQassas I, Merdad R, Maniyar A, et al. Prevalence of Glaucoma in Patients with Obstructive Sleep Apnea. J Epidemiol Glob Health. 2019 Sep;9(3):198-203. doi: 10.2991/jegh.k.190816.001 [Crossref] [PubMed][Google Scholar]

36. Bulpitt CJ, Hodes C, Everitt MG. Intraocular pressure and systemic blood pressure in the elderly. $\mathrm{Br}$ J Ophthalmol. 1975 Dec;59(12):717-20. doi: 10.1136/bjo.59.12.717 [Crossref][PubMed][Google Scholar]

37. Shiose Y, Kawase Y. A new approach to stratified normal intraocular pressure in a general population. Am J Ophthalmol. 1986 Jun 15;101(6):714-21. doi: 10.1016/0002-9394(86)90776-2

[Crossref]

[PubMed][Google Scholar]

38. Klein $B E$, Klein $R$, Linton $\mathrm{KL}$. Intraocular pressure in an American community, The Beaver Dam Eye Study. Invest Ophthalmol Vis Sci. 1992 Jun;33(7):2224-8. [Crossref][PubMed][Google Scholar]

39. Mori K, Ando F, Nomura H, Sato Y, Shimokata H. Relationship between intraocular pressure and obesity in Japan. Int J Epidemiol. 2000 Aug;29(4):661-6. doi: 10.1093/ije/29.4.661 [Crossref][PubMed][Google Scholar]

40. Leske MC, Connell AM, Wu SY, Hyman LG, Schachat AP. Risk factors for open-angle glaucoma. The Barbados Eye Study. Arch Ophthalmol. 1995 Jul;113(7):918-24.

doi:

10.1001/archopht.1995.01100070092031

[Crossref][PubMed][Google Scholar]

41. Zang EA, Wynder EL. The association between body mass index and the relative frequencies of diseases in a sample of hospitalized patients. Nutr Cancer. 1994;21(3):247-61. doi: 10.1080/01635589409514323 [Crossref][PubMed] [Google Scholar]

42. Gasser P, Stümpfig D, Schötzau A, AckermannLiebrich $U$, Flammer J. Body mass index in glaucoma. J Glaucoma. 1999 Feb;8(1):8-11. [Crossref][PubMed][Google Scholar]

43. Pépin JL, Chiquet $C$, Tamisier $R$, Lévy $P$, Almanjoumi A, Romanet JP. Frequent loss of nyctohemeral rhythm of intraocular pressure restored by nCPAP treatment in patients with severe apnea. Arch Ophthalmol. 2010 Oct;128(10):125763. doi: 10.1001/archophthalmol.2010.220 [Crossref][PubMed][Google Scholar]
44. Sergi M, Salerno DE, Rizzi M, Blini M, Andreoli A, Messenio $D$, et al. Prevalence of normal tension glaucoma in obstructive sleep apnea syndrome patients. J Glaucoma. 2007 Jan;16(1):42-6. doi: 10.1097/01.ijg.0000243472.51461.24 [Crossref] [PubMed][Google Scholar]

45. Karakucuk S, Goktas S, Aksu M, Erdogan N, Demirci $S$, Oner $A$, et al. Ocular blood flow in patients with obstructive sleep apnea syndrome (OSAS). Graefes Arch Clin Exp Ophthalmol. 2008 Jan;246(1):129-34. doi: 10.1007/s00417-0070656-8 [Crossref][PubMed][Google Scholar]

46. Silva, Maria Rosa Bet de Moraes, and Silke Anna Theresa Weber. "Study on 24 hours IOP study and glaucoma frequency in patients with obstructive sleep apnea syndrome. " Revista Brasileira de Oftalmologia 68. 6 (2009): 338-343. [Crossref] [PubMed][Google Scholar]

47. Bixler EO, Vgontzas AN, Lin HM, Ten Have T, Rein J, Vela-Bueno A, et al. Prevalence of sleepdisordered breathing in women: effects of gender. Am J Respir Crit Care Med. 2001 Mar;163(3 Pt 1):608-13. doi: 10.1164/ajrccm.163.3.9911064 [Crossref][PubMed][Google Scholar]

48. Heinzer R, Vat $S$, Marques-Vidal P, Marti-Soler $H$, Andries D, Tobback N, et al. Prevalence of sleepdisordered breathing in the general population: the HypnoLaus study. Lancet Respir Med. 2015 Apr;3(4):310-8. doi: 10.1016/S2213-2600 (15)00043-0 [Crossref][PubMed][Google Scholar]

49. Emanuel ME, Gedde SJ. Indications for a systemic work-up in glaucoma. Can J Ophthalmol. 2014 Dec;49(6):506-11. doi: 10.1016/j.jcjo.2014.10.001 [Crossref][PubMed] [Google Scholar]

50. Lindberg E, Carter N, Gislason T, Janson C. Role of snoring and daytime sleepiness in occupational accidents. Am J Respir Crit Care Med. 2001 Dec 1;164(11):2031-5. doi: 10.1164/ajrccm.164. 11.2102028 [Crossref][PubMed][Google Scholar]

51. Koskenvuo M, Partinen M, Kaprio J. Snoring and disease. Ann Clin Res. 1985;17(5):247-51. [Crossref][PubMed][Google Scholar]

52. Jennum $P$, Hein $H O$, Suadicani $P$, Gyntelberg $F$. Cardiovascular risk factors in snorers- A 2crosssectional study of 3,323 men aged 54 to 74 years: the Copenhagen Male Study. Chest. 1992 Nov;102(5):1371-6. doi: 10.1378/chest.102.5.1371 [Crossref][PubMed][Google Scholar] 
53. Dielemans I, Vingerling JR, Algra D, Hofman A, Grobbee DE, de Jong PT. Primary open-angle glaucoma, intraocular pressure, and systemic blood pressure in the general elderly population- The Rotterdam Study. Ophthalmology. 1995 Jan;102(1):54-60. doi: 10.1016/s01616420(95)31054-8 [Crossref][PubMed][Google Scholar]

54. Leighton DA, Phillips CI. Systemic blood pressure in open-angle glaucoma, low tension glaucoma, and the normal eye. $\mathrm{Br} \mathrm{J}$ Ophthalmol. 1972 Jun;56(6):447-53. doi: 10.1136/bjo.56.6.447 [Crossref][PubMed][Google Scholar]

55. Graham SL, Drance SM, Wijsman K, Douglas GR, Mikelberg FS. Ambulatory blood pressure monitoring in glaucoma, The nocturnal dip. Ophthalmology. 1995 Jan;102(1):61-9. doi: 10.1016/s0161-6420(95)31053-6 [Crossref] [PubMed][Google Scholar]
56. Leroy $M$, Van Surell $C$, Pilliere $R$, Hagenmuller $M P$, Aegerter $P$, Raffestin $B$, et al. Short-term variability of blood pressure during sleep in snorers with or without apnea. Hypertension. 1996 Dec;28(6):937-43. doi: 10.1161/01.hyp.28.6.937 [Crossref][PubMed][Google Scholar]

57. Shepard JW Jr, Garrison MW, Grither DA, Dolan GF. Relationship of ventricular ectopy to oxyhemoglobin desaturation in patients with obstructive sleep apnea. Chest. 1985 Sep;88(3):335-40. doi: 10.1378/chest.88.3.335 [Crossref][PubMed][Google Scholar]

58. Boland MV, Quigley HA. Risk factors and openangle glaucoma: classification and application. J Glaucoma. 2007 Jun-Jul;16(4):406-18. doi: 10.1097/IJG.0b013e31806540a1 [Crossref] 